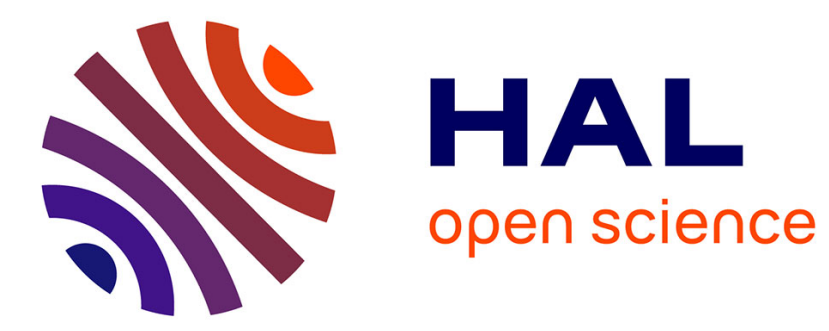

\title{
CVD Copper Deposition from CuI(HFAC)TMVS Studied Through a Modeling Experimental Design
}

\author{
J.-L. Mermet, M.-J. Mouche, F. Pires, E. Richard, J. Torres, J. Palleau, F.
}

Braud

\section{- To cite this version:}

J.-L. Mermet, M.-J. Mouche, F. Pires, E. Richard, J. Torres, et al.. CVD Copper Deposition from CuI(HFAC)TMVS Studied Through a Modeling Experimental Design. Journal de Physique IV Proceedings, 1995, 05 (C5), pp.C5-517-C5-523. 10.1051/jphyscol:1995560 . jpa-00253922

HAL Id: jpa-00253922

https://hal.science/jpa-00253922

Submitted on 1 Jan 1995

HAL is a multi-disciplinary open access archive for the deposit and dissemination of scientific research documents, whether they are published or not. The documents may come from teaching and research institutions in France or abroad, or from public or private research centers.
L'archive ouverte pluridisciplinaire HAL, est destinée au dépôt et à la diffusion de documents scientifiques de niveau recherche, publiés ou non, émanant des établissements d'enseignement et de recherche français ou étrangers, des laboratoires publics ou privés. 


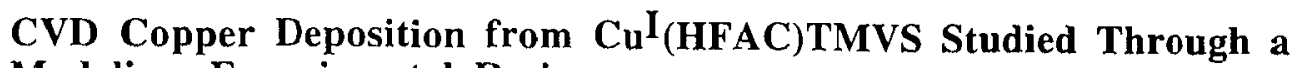 Modeling Experimental Design
}

\author{
J.-L. Mermet, M.-J. Mouche, F. Pires, E. Richard, J. Torres*, J. Palleau* and F. Braud* \\ CENG, D. LETI-D. MEL, 17 rue des Martyrs, 38054 Grenoble cedex 9, France \\ * CNET-TPM, Chemin du Vieux Chêne, BP. 98, 38243 Meylan cedex, France
}

\begin{abstract}
Thin copper films were grown using hexafluoroacetylacetonato-copper(I) trimethylvinylsilane [ $\mathrm{Cu}(\mathrm{hfac}) \mathrm{tm} v \mathrm{~s}]$. This precursor was delivered through a bubbler using hydrogen as carrier gas. Water vapour was used as reactant. The films were deposited on sputtered titanium nitride substrate, at wafer temperatures between $100^{\circ} \mathrm{C}$ and $210^{\circ} \mathrm{C}$.

An excess of water leads to the formation of copper oxide and films with a high resistivity. But no water leads to a poor nucleation and very low deposition rate. The way of injecting water plays an important role in the process : water at the beginning of the deposition time helps the nucleation and has to be stopped after a few minutes to avoid the oxidation of the film.

An optimization of the operating conditions was carried out through the use of screening and modeling experimental designs. The influence of substrate temperature, carrier gas flow, water flow, water injection time and bubbler pressure was studied and leads to experimental laws, which are showing the dependence of the resistivity and the deposition rate with any of these parameters. An optimum working point was found, in term of resistivity. In that case, X-Ray Photoelectron Spectroscopy (XPS) indicate a pure copper phase. The resistivity was $1.9 \mu \Omega$.cm after annealling. The adhesion on TiN substrate is excellent according to the "scotch tape" test. Very high conformal deposition is obtained on $0,4 \mu \mathrm{m}$ width, $1 \mu \mathrm{m}$ deep.
\end{abstract}

\section{INTRODUCTION}

As devices dimensions continue to shrink in the silicon based microelectronics industry, it is more and more difficult to achieve good step coverage using only the conventional sputtering technology [1]. So, CVD method presents several advantages such as conformal coverage and possible selective deposition. Due to its low resistivity and high electromigration resistance, copper is widely predicted to be the interconnect material replacing aluminium, or aluminium alloys, [2] for technologies below $0.25 \mu \mathrm{m}$.

Therefore, copper $\mathrm{CVD}$ has been of large interest recently, particularly with the use of $\mathrm{Cu}(\mathrm{I})$ and $\mathrm{Cu}(\mathrm{II}) \mathrm{B}$ diketonate precursors $[3,4]$. The $\mathrm{Cu}(\mathrm{I})$ compounds such as $\left(\beta\right.$-diketonate) $\mathrm{Cu} \mathrm{L}_{\mathrm{n}}$, where $\mathrm{L}$ is an organic donor ligand as Lewis base (e.g.: PMe 3 ) [5], alkenes (e.g.: TMVS, COD) [6,7], alkynes (e.g.: 2-butyne) [8] lead to a copper deposition via a bimolecular disproportionation reaction [3,4] (equation 1). The $\mathrm{Cu}(\mathrm{II})$ precursors such as $\mathrm{Cu}(\beta \text {-diketonate })_{2}$ (e.g.: $\left.\mathrm{Cu}(\mathrm{acac})_{2}, \mathrm{Cu}(\mathrm{hfac})_{2}\right)[9,10]$ require the presence of an external reducing agent such as hydrogen [11] to produce clean films (equation 2).

Equation 1 (Disproportionation): $\quad 2(\beta-$ diketonate $) C u^{l} L_{n} \rightarrow C u^{o}+C u^{\prime \prime}(\beta-\text { diketonate })_{2}+2 n L$

Equation 2 (Reduction): $\quad C u^{\prime \prime}(\beta-\text { diketonate })_{2}+H_{2} \rightarrow C u^{0}+2(\beta-$ diketone $)$ 
Copper $\mathrm{CVD}$ deposition process using $\mathrm{Cu}(\mathrm{I})$ precursors can be performed at lower temperatures, typically $200^{\circ} \mathrm{C}$, but $\mathrm{Cu}(\mathrm{I})$ compounds tend to be unstable during storage. On the other hand, $\mathrm{Cu}(\mathrm{II})$ precursors require higher deposition temperature [12], but are more stable at room temperature.

This study is carried out using the $\mathrm{Cu}(\mathrm{I})$ compound: hexafluoroacetylacetonato copper(I) trimethylvinylsilane $[\mathrm{Cu}(\mathrm{hfac}) \mathrm{tmvs}]$, wich is today mostly used in the industrial field. Preliminary results are presented beneath.

\section{EXPERIMENTAL SET UP}

\subsection{Description}

Experiments are carried out in an home-made Ultra High Vacuum CVD reactor for 4" wafers, schematically shown in Figure 1. The deposition is made after obtaining a residual gas pressure below $10^{-7}$ Torr in the reaction chamber.

The precursor $[\mathrm{Cu}(\mathrm{hfac}) \mathrm{tm} v \mathrm{~s}]$, Cupraselect ${ }^{\mathrm{TM}}$ of Schumacher is delivered through a bubbler using hydrogen as carrier gas. Water vapour is used as reactant and is delivered in the reaction chamber through an independant line. The two lines are heated to avoid any condensation.

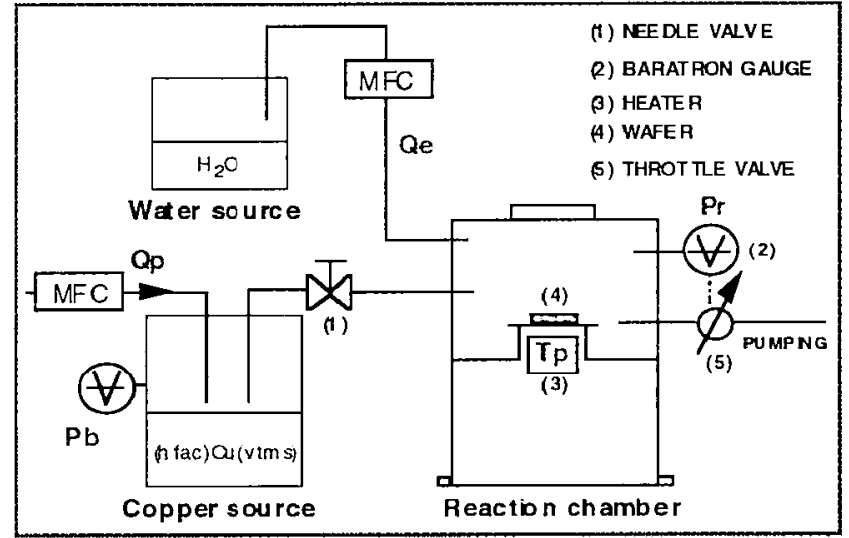

Figure 1 : Experimental set-up

\begin{tabular}{|ll|l|}
\hline \multicolumn{1}{|c|}{ Parameters } & \multicolumn{1}{c|}{ Values } \\
\hline WalerTemp. & $T_{c}$ & $10^{\circ} \mathrm{C}-210^{\circ} \mathrm{C}$ \\
CarrierGasflow & $Q_{p}$ & $50 s \mathrm{~cm}-100 \mathrm{sccm}$ \\
Waterflow & $Q_{e}$ & $1,2 \mathrm{scan}-4 \mathrm{socm}$ \\
Reaction Pressure & $P_{r}$ & 0,3 Torr -2 Torr \\
BubblerPressure & $P_{b}$ & 8,5 Torr -20 Torr \\
Timewithout Water & $T_{s a r s}$ & $0 \mathrm{~min}-30 \mathrm{~min}$ \\
Timewith water & $T_{e}$ & $2 \mathrm{~min}-10 \mathrm{~min}$ \\
\hline
\end{tabular}

Table 1 : Deposition parameters

\subsection{Experimental conditions}

The films are deposited on a $60 \mathrm{~nm}$ sputtered Titanium Nitride layer on 4" silicon substrates. Early deposition experiments on "old" wafers without cleaning have shown a very poor nucleation. Consequently, before deposition, the wafers are chemically cleaned in an $\mathrm{NH}_{4} \mathrm{OH} / \mathrm{H}_{2} \mathrm{O}_{2}$ solution, in order to remove the surface contamination.

Surface resistance of the copper films is measured with a four probe technique and the layer thickness is measured on a step chemically etched.

The amount of injected water has a drastic influence on the layer resistivity : too much water leads to oxidized films, and without water to a poor nucleation. That is why we take as parameters the water thow and also the duration of water injection: it is delivered at the beginning of deposition (to improve nucleation) and then stopped (to avoid oxide formation).

The CVD deposition parameters for experiments are listed in Table 1 . The lemperature of the copper precursor bubbler is fixed at $40^{\circ} \mathrm{C}$, the precursor line at $50^{\circ} \mathrm{C}$ and the reaction chamber walls at $60^{\circ} \mathrm{C}$. 


\section{MODELING EXPERIMENTAL DESIGN}

\subsection{Presentation}

A modeling experimental design is used 10 study the influence of the parameters listed above. In that way, we don't vary each parameter one after the other, but we are looking for experimental laws between the responses (resistivity and thickness) and the deposition parameters. So, the goal is to find out the "B coefficents" of a second degree law such as:

$$
Y=B_{0}+\sum B_{i} X_{i}+\sum_{i \neq j} B_{i j} X_{i} X_{j}+\sum B_{i i} X_{i}^{2}
$$

where $\mathrm{Y}$ is one response and $\mathrm{X}_{\mathrm{i}}$ the parameters.

We have used "Echip" [13] software, wich defines the best way to perform the experiments in our experimental field (minimum number of experiments for the best accurancy and fitting between the experimental results and the calculated laws); it is based on Hadamard matrix $[14,15]$.

As seven parameters would have required too many experiments, we have kept the reaction pressure (Pr) constant and egal to 0.5 Torr : this value has given the best results in terms of resistivity and deposition rate in our preliminary experiments, in agreement with the main literature results $[16,17]$.

Considering the six remaining parameters, the software has required a set of 33 experiments to find out the twenty eight $\mathrm{B}$ coefficients for each response.

\subsection{Results}

After getting the two general laws for resistivity and for thickness, we have studied the parameters giving the optimum value for resistivity. They are listed in table 2 . The corresponding values for resistivity and thickness are respectively $2.3 \mu \Omega . \mathrm{cm}$ and $435 \mathrm{~nm}$.

The resistivity value used in the modeling experimental design is taken from "as deposited" lilms; subsequent annealing lead to improved values, as described in $\$ 4$.

To understand the intluence of the various parameters, we have studied the laws variations around this optimum point for resistivity. The following discussion is valid only around this point.

Results are summarized in figures 2 to 9 , showing the dependences of thickness and resistivity with cach deposition parameter, keeping all other parameters constant at the values giving the optimum resistivity. We have usually considered the average deposition rate (thickness divided by the overall deposition time) instead of thickness, because it is physically more relevant.

\begin{tabular}{|ll|l|}
\hline \multicolumn{2}{|c|}{ Parameters } & \multicolumn{1}{c|}{ Values } \\
\hline Wafer Temp. & $\mathrm{Tc}$ & $190^{\circ} \mathrm{C}$ \\
Carrier Gas Flow & $\mathrm{Qp}$ & $100 \mathrm{sccm}(\mathrm{H} 2)$ \\
Water Flow & $\mathrm{Qe}$ & $2,4 \mathrm{sccm}$ \\
Reaction Pressure & $\mathrm{Pr}$ & 0,5 Torr \\
Bubbler Pressure & $\mathrm{Pb}$ & 12,5 Torr \\
Time without Water & $\mathrm{Tsans}$ & $27 \mathrm{~min}$ \\
Time with water & $\mathrm{Te}$ & $2 \mathrm{~min}$ \\
\hline
\end{tabular}

Table 2 : Deposition parameters giving the optimum resistivity, according to the modeling experimental design

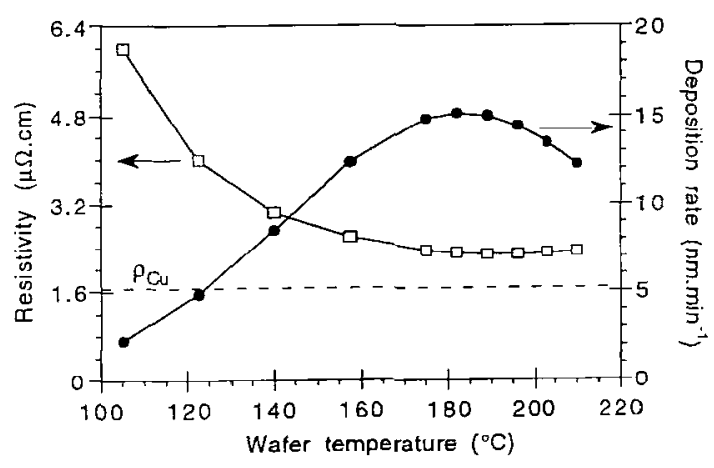

Figure 2 : Resistivity and thickness versus wafer temperature 


\subsubsection{Wafer temperature :}

We observe on figure 2 that increasing temperature above $170{ }^{\circ} \mathrm{C}$ do not improve neither the deposition rate nor the resistivity; on the contrary, parasite reactions or homogeneous reactions occur and lead to some decrease in the deposition rate. Figure 3 shows clearly the change from a kinetic reaction control to a mass transport one, around $170^{\circ} \mathrm{C}$.

The activation energy found in the kinetic control regime (slop of the curve) is $44 \mathrm{kcal} / \mathrm{mol}$. This value is in agreement with most of the literature values $[18,19]$.

The high values for resistivity at low temperature are explained by a reduced thickness (these layers have thicknesses around $50-100 \mathrm{~nm}$ ) and by the poor coalescence mechanism, due to the fact that each grain boudarie acts as an electrical resistance.

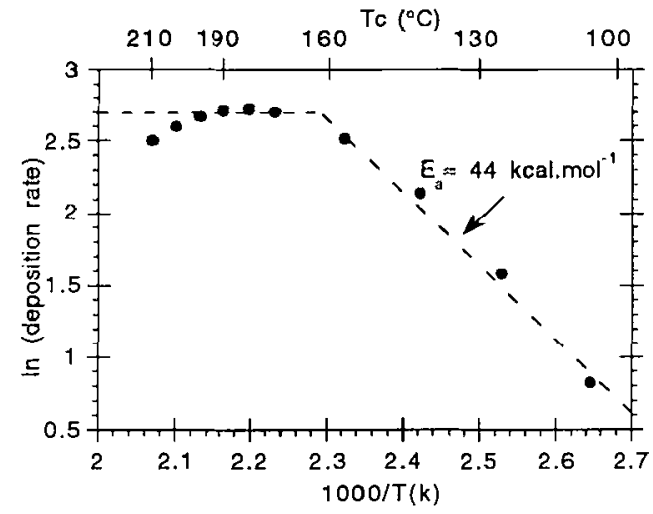

Figure 3 : Deposition rate (ln) versus inverse temperature

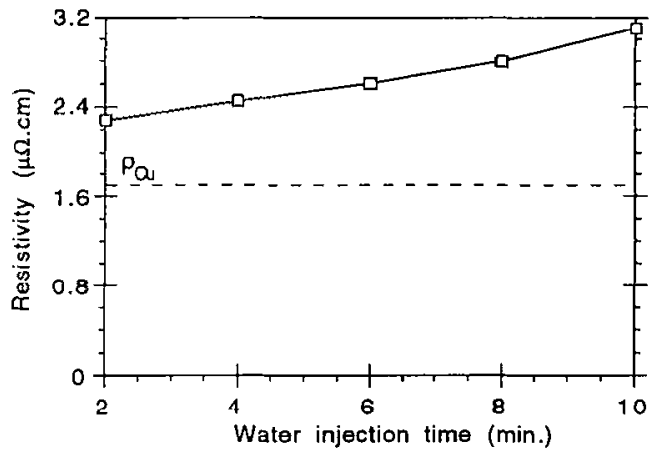

Figure 4 : Resistivity versus water injection duration

\subsubsection{Injection duration, with and without water:}

For a given water flow of $2.4 \mathrm{sccm}$, figure 4 shows that the resistivity increases continuously with the water injection time. Figure 5 shows the dependence of thickness versus deposition time, for several water injection times. We clearly see that:

- the deposition rate with water is constant, $(28 \mathrm{~nm} / \mathrm{mn})$ in these conditions.

- the deposition rate without water is depending on the water injection time.

This last point is explained as follows: it is likely that water plays a role during the nucleation stage through increasing nuclei density and hence the resistivity and the deposition rate.

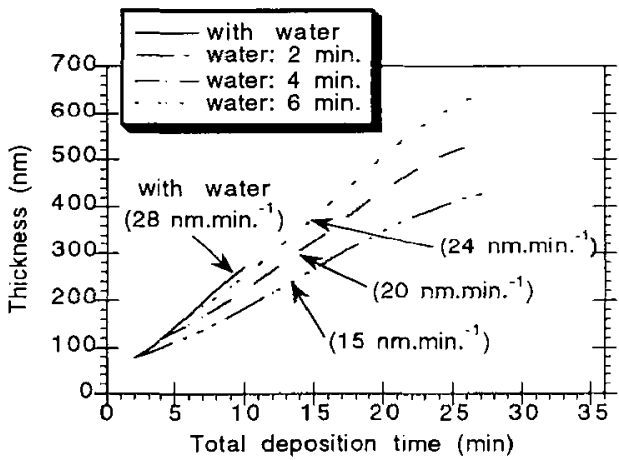

Figure 5 : Thickness versus deposition time, for different times with water

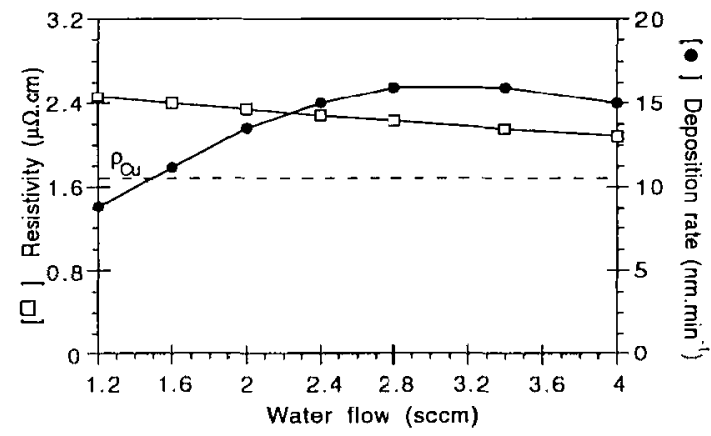

Figure 6 : Resistivity and deposition rate versus water flow 


\subsubsection{Water flow:}

Increasing the water flow from 1.2 to $2.8 \mathrm{sccm}$ (cf figure 6), at a given water time of 2 min, increases a lot the deposition rate which then decreases when the water flow becomes higher than $3.6 \mathrm{sccm}$. Resistivity decreases slightly but continuously when water flow increases.

Theses effects are due to the improved nucleation process with water injection, as explained above. With a certain amount of water (through time or flow), the maximum density of nuclei is achieved and more water does not improve the depositon rate.

\subsubsection{Carrier flow :}

We observe on figure 7 a very low influence of the carrier gas on both resistivity and deposition rate. This is because changing the carrier gas flow does not change the partial pressures in the reaction chamber but only the exposure time, which has a very low impact.

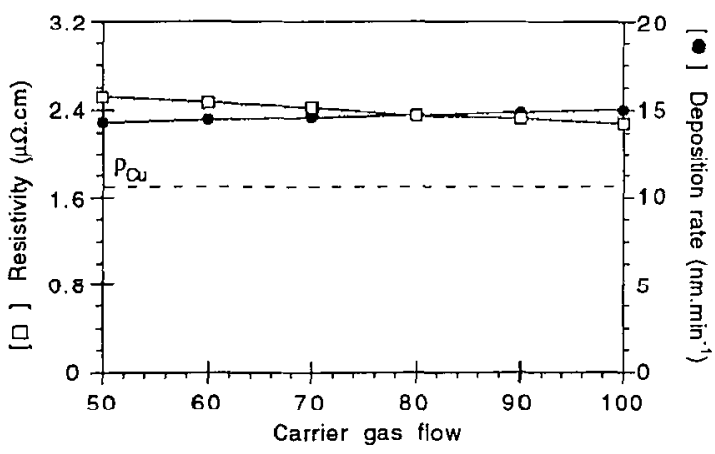

Figure 7 : Resistivity and deposition rate versus carrier gas flow

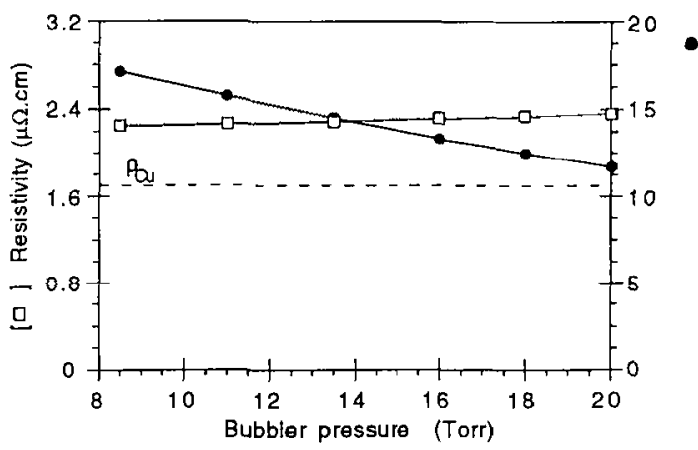

Figure $8:$ Resistivity and deposition rate versus bubbler pressure

\subsubsection{Bubbler pressure :}

This parameter is adjusted using the manual needle valve ((1) on Figure 1). As the precursor vapor pressure is fixed by the bubbler temperature $\left(0.35\right.$ Torr at $\left.40^{\circ} \mathrm{C}\right)$, changing the bubbler pressure changes the ratio $\mathrm{P}_{\mathrm{H} 2} / \mathrm{P}$ Precursor inside the bubbler and consequently the precursor partial pressure in the reaction chamber.

We can see in figure 8 that, according to the diffusion regime, bubbler pressure affects directly the deposition rate. The resistivity is very slightly affected, due to a better nucleation density when the precursor partial pressure is higher. We assume that a higher precursor partial pressure leads to higher nuclei density and a better resistivity due to the fact that more contact points exists between the copper grains.

\section{ANNEAL INFLUENCE}

Some annealing treatments have been performed after deposition in order to reduce the layers resistivity. The applied conditions were $450^{\circ} \mathrm{C}$ during 30 minutes. This annealling has an influence on the layers microstructure but not on their composition.

We can see on figure 9-a/ a micrograph of the layer obtained in the optimum conditons reported in the figure caption. The resistivity decreases to $1.9 \mu \Omega . \mathrm{cm}$ after anneal and figure 9 -b/ shows its new morphology.

Figure 10 shows an XPS spectrum on that layer, which is identical before and after anneal; in both cases it is pure copper. 


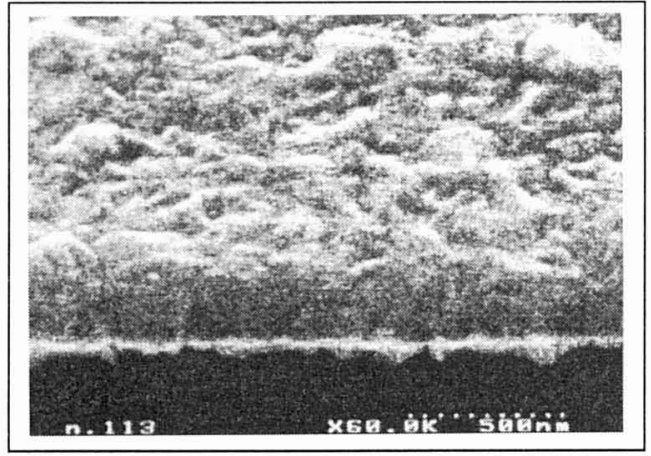

$$
\mathbf{t}=230 \mathrm{~nm}, \rho=2,4 \mu \Omega . \mathrm{cm}
$$

a/

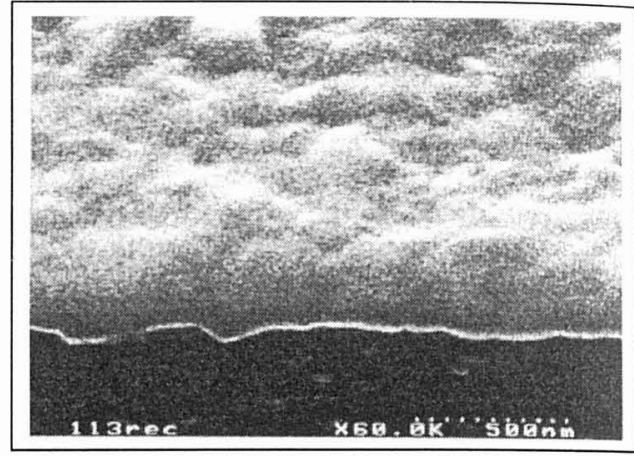

$\mathbf{t}=220 \mathrm{~nm}, \rho=1,9 \mu \Omega . \mathrm{cm}$

b/

Figure 9 : Morphologies of the same copper film (experimental parameters: $\mathrm{Tp}=158^{\circ} \mathrm{C}, \mathrm{Pr}=0,5 \mathrm{Torr}$, $\mathrm{Pb}=14,6$ Torr $, \mathrm{Qe}=1,3 \mathrm{sccm}, \mathrm{Qp}($ with $\mathrm{H} 2)=50 \mathrm{sccm}$, Tsans $=30 \mathrm{~min}$, Teau $=2 \mathrm{~min})$ helore $(\mathrm{a} /)$ and after $(\mathrm{b} /)$ annealling.
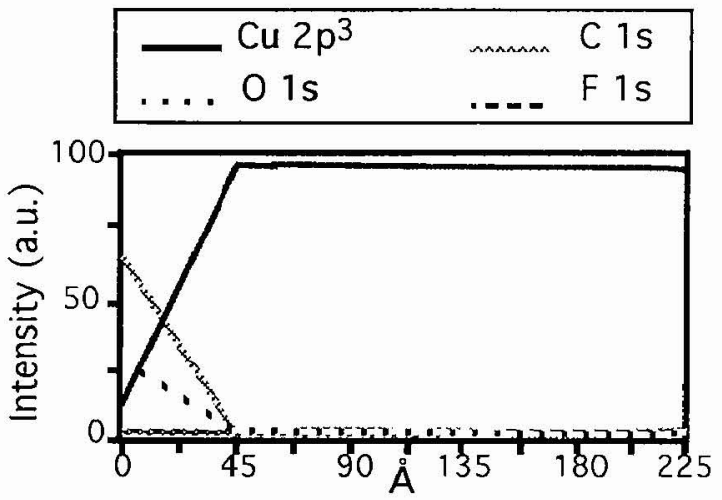

Figure 10 : XPS in-depth profiles (by ionic abrasion) of a copper film obtained in conditions listed above.

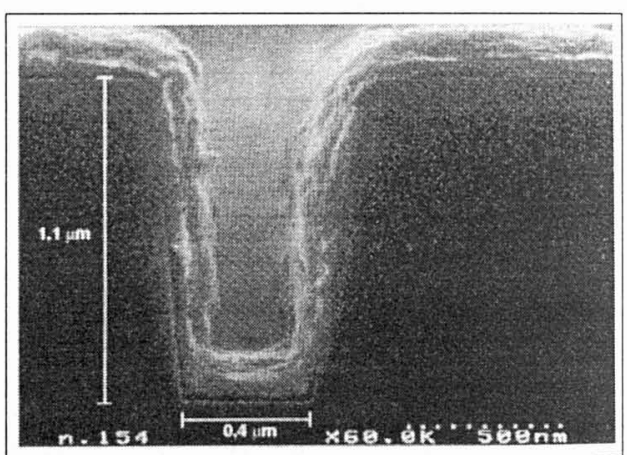

Figure 11 : Step coverage on hole $0,4 \mu \mathrm{m} \times 1,1 \mu \mathrm{m}$.

\section{DEPOSITION ON TOPOLOGIES}

Depositions have been done on structures with holes of $0.4 \mu \mathrm{m}$ diameter and $1,1 \mu \mathrm{m}$ depth. The substrate was composed of $40 \mathrm{~nm}$ sputtered titanium deposited on $60 \mathrm{~nm}$ sputtered TiN on silicon. Figure 11 shows a very conformal deposition with a step coverage value around $90 \%$. This result is obtained at a reaction pressure of 0.5 Torr and wafer temperature of $160^{\circ} \mathrm{C}$. 


\section{CONCLUSION}

High purity copper layers have heen ohtained on titanium nitride substrates. The scotch test shows an excellent adhesion. The resistivity and step coverage are very good and allow to use this material in the futur microelectronic technologies.

The quite low deposition rate (around $15 \mathrm{~nm} / \mathrm{min}$ ) is due to the design of both reaction chamber and bubbler, which were not appropriated for that application.

The study clearly shows the interest to use water only at the beginning of the process; 2 minutes at 2.4 sccm are sufficient to induce a good nucleation without any oxidation of the film, and then a high quality layer growth.

\section{ACKNOWLEDGEMENT}

Special thanks to Robert CIMARD lor his technical help, and to Dominique PONCET and Jean-Pierre CAIRE for their helpful discussions in modeling experiments design. We would like also to acknowledge Anne ERMOLIEFF and Jean PIAGUET for their support in analysing the thin films.

\section{REFERENCES}

[1] KUSAKABE Y., OHNISHI H., TAKAHAMA T., GOTO Y. and MACHIDA K., Appl. Surl. Sci. 70/71(1993) 763

12] MARTINEZ-DUART J.M. and ALBELLA J.M., Vacuum, 39(1989) 749.

13] COHEN S.L., LIEHR M. and KASI S., Appl. Phys. Lett. 60(1992) 50.

14] KALOYEROS A.E. and FURY V., MRS Bulletin 18(1993) 22.

[5] SHIN H.K., CHI K-M., JAIN A., HAMPDEN-SMITH M-J., KODAS T.T., FARKAS J., PAFFETT M.F. and FARR J.D., Advanced Metallization for ULSI Applications - MRS (V.S. Rana, R.V. Jushi and I. Ohdomari, Pittshurgh, 1992) p.403.

[6] REYNOLDS S.K., SMART C.J., BARAN E.F., BAUM T.H., LARSON C.E.and BROCK P.J., Appl. Phys. Lett. 59(1991) 2332.

[7] JAIN A., CHI K-M., KODAS T.T. and HAMPDEN-SMITH M-J., J. Electrochem. Soc. 140(1993) 1434

18] BAUM T.H. and LARSON C.E., J. Electrochem. Soc. 140(1993) 154.

19) CHANG Y-N. and SCHRADER G.L. Advanced Metallization for ULSI Applications - MRS, (T.S. Cale and F.S. Pintchovski, Pitusburgh, 1993) p.141.

[10] KIM D.H., WENTORF R.H. and GILL W.N., J. Electrochem. Soc. 140(1993) 3267.

[1 i] VAN HEMERT R.L., SPENDLOVE L.B. and SIEVERS R.E., J. Electrochem. Soc. $112(1965) 1123$.

[12] LECOHIER B., CALPINI B., PHILIPPOZ J-M., VAN DEN BERGH H., LAUB D. and BUFFAT P.A., J. Electrochem. Soc. 140(1993) 789.

113] WHEELER B., Echip Version 6.() for Windows reference manual, (1993).

[14] BOX G.E.P., The collected works of G.E.P Box (The wadsworth statistics / probability series Belmond, California, 1985).

[15] WYNN H.P., "The sequential generation of D.optimal experimental designs", Ann. Math. Statist, 41(1970) 1655-1664.

[16] CHIOU J.C., CHEN Y.J., J. Electronic. Mat. 23 n $^{\circ}$ 4(1994) .

[17] GELATOS A.V., POON S., MARSH R, Bulletin MRS. $19 \mathbf{n}^{\circ} \mathbf{8}(1994)$.

[18] JAIN A., CHI K.M., KODAS T.T. and HAMPDEN-SMITH M-J., J. Electrochem. Soc. $140 n^{\circ} 5$ (1993) 1434-1439.

[19] STUMM T.H. and BERGH V.D., Mat.Sci. and Eng. B 23(1994) 48-53. 